\title{
Fingerprint Analysis in Relation to Blood Group and Gender in the Saudi Arabian Population
}

\author{
Vasanthakumar Packirisamy, ${ }^{1}$ R A. Abudalo, ${ }^{1}$ Zainab Ali I. Alkhars, ${ }^{1}$ Sarah Shaker A. Alalawi, ${ }^{1}$ Mariam Ahmed Abdulhadi \\ Alquraini, ${ }^{1}$ Aljawharah Adnan I. Alfawzan'1
}

${ }^{1}$ Department of Anatomy, College of Applied Medical Sciences, King Saud Bin Abdulaziz University for Health Sciences, Al Ahsa, Saudi Arabia

Disclose and conflicts of interest: none to be declared by all authors

\begin{abstract}
Objective: fingerprints are permanent and an individual physical characteristic, and are considered an authentic proof of identification. The aim of the present study was to investigate whether fingerprints have any significant relationship with gender and blood group.

Materials and Methods: the fingertip patterns of 400 Saudi subjects were recorded using ink and paper, and identified by magnification lens, and the blood group was determined by the agglutination method. After recording the blood group and fingerprints of the subjects of both genders, their correlation was analyzed by Chisquared test.

Results most subjects (49.25\%) belonged to blood group O, followed by A, B and AB, of which $92 \%$ were Rhesus (Rh) positive; the relationship between gender and blood group was statistically significant. Regarding the fingertip patterns among the genders and $\mathrm{ABO}$ and $\mathrm{Rh}$ factor blood groups, loopsweremore frequent, followed by whorls and arches. Regardless of the Rh factor, the fingerprint pattern in blood groups $A$ and $A B$ was statistically significant, but it was not significant in the $B$ and $O$ groups. The incidence of loops was higher on the middle and little fingers, as well as on the thumb, in blood groups A, B and 0 , and this relationship was statistically significant.
\end{abstract}

Conclusions: the present study reveals that the fingerprint pattern is not associated.

Keywords: Blood group; Dermatoglyphics; fingerprint; Gender; Identification

\section{Introduction}

Dermatoglyphics is the scientific study of human epidermal ridges and their pattern on the volar aspect of the palmar and plantar regions. ${ }^{1}$ Fingerprints play an important role in increasing friction and the tactile sensation. The epidermal ridges start to appear on the digits, palms, soles and toes between the 11th and the 16th weeks postfertilization, and their development and differentiation ends by the 24th week. ${ }^{2}$ The fingerprint patterns are absolutely individual and con-stant, even in monozygotic twins, from birth to death. ${ }^{3}$ The permanence of the fingerprint frictional ridges is attributed to three structural features of the volar skin: the attachment of the skin epidermal cells to each other, and the attachment of the basement membrane to the stratum basale layer of the epidermis and to the dermis. ${ }^{4}$ Henry Faulds ${ }^{5}$ proposed the uniqueness and individuality of the fingerprint pattern. Galton ${ }^{6}$ classified the primary human fingerprint configuration into three classes: arches, loops, and whorls. Nowadays, fingerprint patterns are used as an inexpensive and infallible gold standard for personal identification in a wide range of fields: in forensic science, for criminal identification; in bank-ing, to authenticate cashless transactions; ${ }^{7}$ and in Medicine, to predict the diagnosis of genetic disorders, for example. ${ }^{8}$

Karl Landsteiner identified the first human ABO blood group system. Clinically, the grouping of blood types is made using the $\mathrm{ABO}$ and Rhesus (Rh) classification systems. Four major blood group types $(\mathrm{A}, \mathrm{B}, \mathrm{AB}$ and $\mathrm{O})$ are categorized based on the presence of the corresponding antigen in the plasma, and the $\mathrm{Rh}$ system is divided into Rh pve (Rhesus positive) and $\mathrm{Rh}$-ve (Rhesus negative) based on the presence or absence of antigen D. The blood group is clinically essential in transfusion medicine, genomic research and organ transplantation, as well as to predict diseases like duodenal ulcer in the O blood group. ${ }^{9} \mathrm{An}$ association has been noted between the distribution of blood groups and fingerprint patterns. ${ }^{10}$ The average distribution of finger-print patterns has been studied in different racial and ethnic groups; ${ }^{11-22}$ unfortunately, there is little published literature on the distribution of fingerprint patterns among the Saudi Arabian population. The purpose of the present investigation was to quantify the distribution of fingerprint patterns on all digits. The secondary aim was to determine the association of fingerprints with blood groups and gender. 


\section{Materials and Methods}

The present study was approved by the Institutional Review Board (IRB) under number SP17/182. All of the participants provided written informed consent prior to the study. A total of 400 Saudi subjects (males: 185; females: 215) aged between 17 and 45 years were enrolled from the staff and medical students at the King Saud Bin Abdulaziz University for Health Sciences from 2017 to 2018. All of the included subjects were healthy, with no genetic disorders, but two male subjects were excluded because they had scars and injuries in one of their fingers. The finger prints were recorded by applying ink to the fingers of the subjects, who then pressed them against paper, as suggested by Cummins and Midlo. ${ }^{1}$ A fingerprint template was created using a white sheet of paper, which consisted of left and right columns, and each columnwas again divided into 5 to record the finger prints of every finger and the thumb. The template also included boxes to record the subject's name, gender, age, $\mathrm{ABO}$ blood group, and $\mathrm{Rh}$ blood type.

The finger prints were recorded by rolling the pulp of each finger on blue stamp ink pads, and then, imprints of the fingerprints of all 10 digits were obtained on the corresponding blocks of the template. Care was taken to prevent smudging; the prints were taken four times, and their pattern (arch; whorl; loop) was studied using a magnifying glass (Fig. 1). The blood groups were identified by the slide agglutination method, by mixing one drop of blood with antiserum (anti-A, anti-B, and anti-D). The distribution of fingertip patterns and their association with gender and $\mathrm{ABO}$ and $\mathrm{Rh}$ blood groups was analyzed by the Chisquared test, with values of $p<$ 0.05 considered significant.
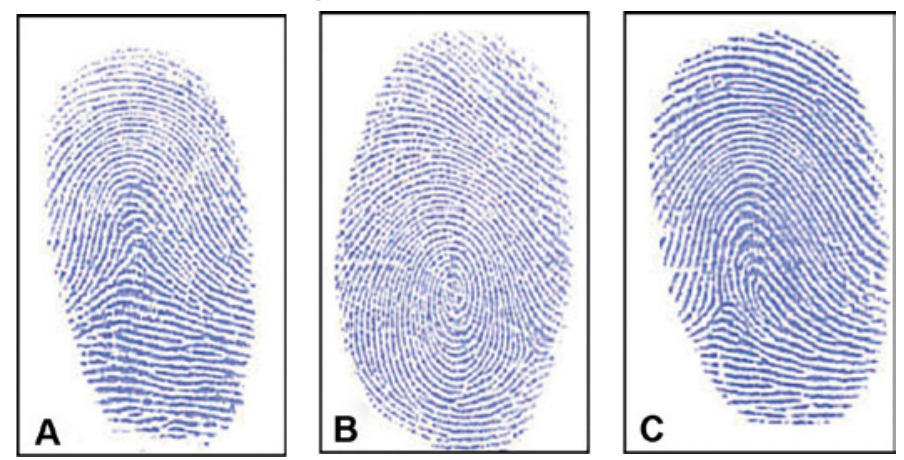

Figure 1. The three primary fingerprint patterns: (A)arch;(B)whorl;(C) loop.

\section{Results}

The sample of the present study consisted of 185 male and 215 female subjects, with a male to female ratio of 1:1.2, and their average age was 21 years.

\section{$\mathrm{ABO}$ and $\mathrm{Rh}$ blood groups}

The Rh pve group was composed of 368 (92\%) subjects, and 184 (46\%) of them belonged to blood group $\mathrm{O}$. The numbers of subjects with blood groups A, B and AB were 85 (21.5\%), 81 (20.25\%) and 18 (4.5\%) respectively.
In the Rh -ve group, out of 32 (8\%) subjects, 13 (3.25\%) belonged blood group $\mathrm{O}$, followed by blood groups $\mathrm{A}$ and $\mathrm{B}$, with 9 (4.5\%) subjects each, and the AB blood group, with 1 (0.25\%) subject (Table 1).

Table 1. Distribution of the subjects according to blood group and Rhesus factor $(n=400)$

\begin{tabular}{l|c|c}
\hline \multirow{2}{*}{ Blood group } & \multicolumn{2}{|c}{ Rhesus factor } \\
\cline { 2 - 3 } & Positive & Negative \\
\hline A & $85(21.25 \%)$ & $9(2.25 \%)$ \\
\hline B & $81(20.25 \%)$ & $9(2.25 \%)$ \\
\hline AB & $18(4.5 \%)$ & $1(0.25 \%)$ \\
\hline O & $184(46 \%)$ & $13(3.25 \%)$ \\
\hline Total $(n)$ & $368(92 \%)$ & $32(8 \%)$ \\
\hline
\end{tabular}

\section{Gender and blood group}

Most subjects $(197 ; 49.25 \%)$ belonged to blood group $\mathrm{O}$, followed by blood groups $\mathrm{A}, \mathrm{B}$ and $\mathrm{AB}$, which were composed of 94 (23.5\%), 90 (22.5\%) and 19 (4.5\%) subjects respectively. After blood group O, the second predominant blood group among males was A (23.24\%), and, in females, it was B (24.19\%), and a statistically significant $(p<0.001)$ difference was observed (Table 2).

\section{Type of finger print patterns}

Loops were the prevailing pattern (50.5\%), followed by whorls (35.1\%) and arches $(14.4 \%)$ on both hands. The frequency of whorls among females (37.49\%) was slightly higher than among males (36.43\%), but the frequency of arches (8.84\%) was the same, while among males, the frequency of loops (56.22\%) was higher than among females (53.67\%). However the relationship between gender and fingerprint pattern was not statistically significant $(p>0.05)$ (Table 3$)$.

\section{Fingerprint patterns regarding}

$\mathrm{ABO}$ and $\mathrm{Rh}$ blood groups In blood group $\mathrm{A}$, the incidence of loops was higher (Rh pve: $58.23 \%$; Rh -ve: $51.11 \%$ ), than that of whorls (Rh pve: $37.53 \%$; Rh -ve: $46.67 \%$ ) and arches (Rh pve: $4.24 ; \mathrm{Rh}$-ve: $2.22 \%$ ). In Blood group $\mathrm{AB}$, the incidence of loops was higher (Rh pve: 61.67\%; Rh -ve: 70\%), followed by arches (Rh pve: $5 \%$; Rh -ve $-30 \%$ ) and whorls (Rh pve: $33.3 \%$; Rh -ve: $0 \%)$. Among the AB Rh -ve blood group, only loops and arches were observed on the fingerprints of the subjects. These differences between the $A$ and $A B$ blood groups were statistically significant $(p<0.05)$.

Among the subjects in blood group $\mathrm{O}$, the incidence of loops was higher (Rh pve: $52.88 \%$; Rh -ve: $52.5 \%$ ), followed by whorls (Rh pve: $38.26 \%$; Rh -ve: 37.69\%) and arches (Rh pve: $8.86 \%$; Rh -ve: 13.08\%). Similarly, in blood group B, loops had a higher incidence (Rh pve: $55.43 \%$; Rh -ve: $54.44 \%$ ), followed by whorls (Rh pve: 33.58\%; Rh -ve: $37.78 \%$ ) and arches (Rh pve: 10.99\%; Rh -ve: 7.78\%). However, the differences between the $\mathrm{O}$ and $\mathrm{B}$ groups were not statistically significant $(p>$ 0.05) (Table 4). 
Table 2. Distribution of subjects according to gender and blood group

\begin{tabular}{|c|c|c|c|c|c|}
\hline Blood group & Males $(n=185)$ & Females $(n=215)$ & Total $(n=400)$ & Chi-squared & $p$-value \\
\hline A & $43(23.24 \%)$ & $51(23.71 \%)$ & $94(23.5 \%)$ & \multirow{5}{*}{47.44} & \multirow{5}{*}{$<0.001$} \\
\hline $\mathrm{AB}$ & $6(3.24 \%)$ & $13(6.05 \%)$ & $19(4.75 \%)$ & & \\
\hline B & $38(20.55 \%)$ & $52(24.19 \%)$ & $90(22.5 \%)$ & & \\
\hline $\mathrm{O}$ & $98(52.97 \%)$ & $99(24.19 \%)$ & $197(49.25 \%)$ & & \\
\hline Total & $185(100 \%)$ & $215(100 \%)$ & $400(100 \%)$ & & \\
\hline
\end{tabular}

Note: *Statistically significant difference.

Table 3. Overall distribution of fingerprint patterns on both hands among males and females $(n=4,000)$

\begin{tabular}{|c|c|c|c|c|c|}
\hline Fingerprint patterns & Male & Female & Total & Chi-squared & $p$-value \\
\hline Arches & $136(7.35 \%)$ & $190(8.84 \%)$ & $326(8.15 \%)$ & \multirow{4}{*}{4.164} & \multirow{4}{*}{$>0.05$} \\
\hline Loops & $1,040(56.22 \%)$ & $1,154(53.67 \%)$ & $2,194(54.85 \%)$ & & \\
\hline Whorls & $674(36.43 \%)$ & $806(37.49 \%)$ & $1,480(37 \%)$ & & \\
\hline Total & $1,850(100 \%)$ & $2,150(100 \%)$ & $4,000(100 \%)$ & & \\
\hline
\end{tabular}

Table 4. Distribution of fingerprint patterns among subjects according to blood group and Rhesus factor $(n=4,000)$

\begin{tabular}{|c|c|c|c|c|c|c|c|}
\hline \multirow{2}{*}{\multicolumn{2}{|c|}{$\begin{array}{c}\text { Blood group } \\
\text { Arches }\end{array}$}} & \multicolumn{4}{|c|}{ Types of fingerprint patterns } & \multirow{2}{*}{ Chi-squared } & \multirow{2}{*}{$p$-value } \\
\hline & & \multirow{2}{*}{$\begin{array}{c}\text { Loops } \\
36(4.24 \%)\end{array}$} & \multirow{2}{*}{$\begin{array}{c}\text { Whorls } \\
495(58.23 \%)\end{array}$} & \multirow{2}{*}{$\frac{\text { Total }}{319(37.53 \%)}$} & \multirow[b]{2}{*}{$850(21.25 \%)$} & & \\
\hline \multirow{2}{*}{ A } & Rh +ve & & & & & \multirow{2}{*}{7.003} & \multirow{2}{*}{$<0.05^{*}$} \\
\hline & Rh -ve & $2(2.22 \%)$ & $46(51.11 \%)$ & $42(46.67 \%)$ & $90(2.25 \%)$ & & \\
\hline \multirow{2}{*}{ B } & $\mathrm{Rh}+\mathrm{ve}$ & $89(10.99 \%)$ & $449(55.43 \%)$ & $272(33.58 \%)$ & $810(20.25 \%)$ & \multirow{2}{*}{1.216} & \multirow{2}{*}{$>0.05$} \\
\hline & Rh -ve & $7(7.78 \%)$ & $49(54.44 \%)$ & $34(37.78 \%)$ & $90(2.25 \%)$ & & \\
\hline \multirow{2}{*}{$A B$} & $\mathrm{Rh}+\mathrm{ve}$ & $9(5 \%)$ & $111(61.67 \%)$ & $60(33.33 \%)$ & $180(4.5 \%)$ & \multirow{2}{*}{10.099} & \multirow{2}{*}{$<0.05^{*}$} \\
\hline & Rh -ve & $3(30 \%)$ & $7(70 \%)$ & 0 & $10(0.25 \%)$ & & \\
\hline \multirow{2}{*}{0} & $\mathrm{Rh}+\mathrm{ve}$ & $163(8.86 \%)$ & $973(52.88 \%)$ & $704(38.26 \%)$ & $1,840(46 \%)$ & \multirow{2}{*}{2.682} & \multirow{2}{*}{$>0.05$} \\
\hline & Rh -ve & $17(13.08 \%)$ & $64(49.23 \%)$ & $49(37.69 \%)$ & $130(3.25 \%)$ & & \\
\hline
\end{tabular}

Abbreviations: Rh pve, Rhesus positive; Rh -ve, Rhesus negative. Note: *Statistically significant difference..

\section{Fingerprint patterns on each finger}

In the subjects with blood groups $A, B$ \& $O$, the incidence of loops was higher on the thumbs (A: $65.43 \%$; B: $63.89 \%$; and O: $62.2 \%$ ), followed by the middle (A: 70.2\%; B: 67.78\%; and O: 62.69\%), and little fingers (A: 64.9\%; B: 63.89\%; and O: 56.60\%), while the incidence of whorls was higher on the index (A: 51.06\%; B: 42.22\%; and O: 47.46\%), and ring fingers (A: 50.53\%,; B: $45.55 \%$; and O: $45.69 \%)$. In the AB blood group, the incidence of loops was higher (54.85\%), followed whorls (37\%) and arches on every finger (8.15\%). As for the incidence of arches, it was lower on the little fingers (A: $1.06 \%$; B: $1.11 \%$; AB: $5.26 \%$; and O: $4.31 \%$ ) and the thumbs (A: $1.06 \%$; B: 3.89\%; AB: 5.26\%; and O: 3.54\%). The fingerprint pattern distribu-tion was statistically significant $(p>0.001)$ in blood groups A, B and O, but not significant in the AB blood group $(p>0.05)$ (Table 5$)$.

\section{Discussion}

In accordance with other studies, ${ }^{11-22}$ the order of distribution of fingerprint patterns in the present study was as follows: a high incidence of loops, a moderate incidence of whorls, and a low incidence of arches. In the comparison between genders, whorls and arches were more predominant in females, and loops were more predominant males. In agreement with that, Ekanem et al, ${ }^{16}$ in a study with residents of Maiduguri, Nigeria, reported a higher incidence of loops (31\%) in males. In contrast, Shivhare et al, ${ }^{11}$ in Chhattisgarh (central India), and Sudikshya et al, ${ }^{12}$ in Nepal, observed a higher incidence of loops in females (55.8\% and $52.4 \%$ respectively), but in males they found a higher incidence of whorls $34.23 \%$ and 43\%respectively) and arches (16.23\% and 5.87\% respectively). Sangam et al,,${ }^{13}$ Deopa et $a l,,^{14}$ and Desai et $a l^{15}$ found a higher incidence of loops $(60.5 \%, 64.53 \%$ and $52.63 \%$ respectively) in females, and, regarding the $\mathrm{ABO}$ groups, most individuals belonged to the $\mathrm{O}$ group, and the $A B$ group had the lowest incidence. A similar observation was noted by Sudikshya et al, ${ }^{12}$ Sangam et $a l,{ }^{13}$ and Bharadwaja et al. ${ }^{17}$ In contrast, Deopa et $a l,{ }^{14}$ in their study in Uttarakhand, India, found that most subjects belonged to blood group B. Fayrouz et $a l^{18}$ reported a significant relationship between gender and blood group, which is in agreement with the present study. The incidence of Rh pve (92\%) subjects 
Table 5. Distribution of fingerprint patterns on different fingers of both hands of the subjects $(n=800[400 \times 2])$

\begin{tabular}{|c|c|c|c|c|c|c|c|c|c|c|c|c|}
\hline \multirow{2}{*}{ Fingers } & \multicolumn{3}{|c|}{ Blood group A $(n=940)$} & \multicolumn{3}{|c|}{ Blood group B $(n=900)$} & \multicolumn{3}{|c|}{ Blood group AB $(n=190)$} & \multicolumn{3}{|c|}{ Blood group $O(n=1970)$} \\
\hline & Arches & Loops & Whorls & Arches & Loops & Whorls & Arches & Loops & Whorls & Arches & Loops & Whorls \\
\hline \multirow{2}{*}{ Thumb } & 2 & 123 & 63 & 7 & 115 & 58 & 2 & 22 & 14 & 14 & 245 & 135 \\
\hline & $1.06 \%$ & $65.43 \%$ & $33.51 \%$ & $3.89 \%$ & $63.89 \%$ & $32.22 \%$ & $5.26 \%$ & $57.90 \%$ & $36.84 \%$ & $3.54 \%$ & $62.20 \%$ & $34.26 \%$ \\
\hline \multirow{2}{*}{ Index } & 10 & 82 & 96 & 32 & 72 & 76 & 3 & 23 & 12 & 51 & 156 & 187 \\
\hline & $5.32 \%$ & $43.62 \%$ & $51.06 \%$ & $17.78 \%$ & $40 \%$ & $42.22 \%$ & $7.90 \%$ & $60.52 \%$ & $31.58 \%$ & $12.94 \%$ & $39.60 \%$ & $47.46 \%$ \\
\hline \multirow{2}{*}{ Middle } & 13 & 132 & 43 & 31 & 122 & 27 & 2 & 28 & 8 & 50 & 247 & 97 \\
\hline & $6.90 \%$ & $70.2 \%$ & $22.9 \%$ & $17.22 \%$ & $67.78 \%$ & $15 \%$ & $5.26 \%$ & $73.70 \%$ & $21.04 \%$ & $12.69 \%$ & $62.69 \%$ & $24.62 \%$ \\
\hline \multirow{2}{*}{ Ring } & 11 & 82 & 95 & 24 & 74 & 82 & 3 & 23 & 12 & 48 & 166 & 180 \\
\hline & $5.85 \%$ & $43.62 \%$ & $50.53 \%$ & $13.33 \%$ & $41.11 \%$ & $45.55 \%$ & $7.90 \%$ & $60.52 \%$ & $31.58 \%$ & $12.18 \%$ & $42.13 \%$ & $45.69 \%$ \\
\hline \multirow{2}{*}{ Little } & 2 & 122 & 64 & 2 & 115 & 63 & 2 & 22 & 14 & 17 & 223 & 154 \\
\hline & $1.06 \%$ & $64.9 \%$ & $34.04 \%$ & $1.11 \%$ & $63.89 \%$ & $35 \%$ & $5.26 \%$ & $57.9 \%$ & $36.84 \%$ & $4.31 \%$ & $56.60 \%$ & $39.09 \%$ \\
\hline Statistics & \multicolumn{3}{|c|}{$\begin{array}{c}\text { Chi-squared }=65.034 \\
p<0.001^{\star *}\end{array}$} & \multicolumn{3}{|c|}{$\begin{array}{c}\text { Chi-squared }=94.154 \\
p<0.001 * *\end{array}$} & \multicolumn{3}{|c|}{$\begin{array}{c}\text { Chi-squared }=3.5678 \\
p>0.05\end{array}$} & \multicolumn{3}{|c|}{$\begin{array}{c}\text { Chi-squared }=111.027 \\
p<0.001^{\star *}\end{array}$} \\
\hline
\end{tabular}

Notes: Values expressed as numbers and percentages. **Statistically significant difference.

was higher in every blood group (Rh -ve: $8 \%$ ), which is similar to other studies ${ }^{15-21}$ performed with different ethnic and racial groups.

In the present study, the frequency of loops and arches was higher in the A Rh pve blood group, and the frequency of whorls was higher in the A Rh - ve group. These differences were statistically significant, which is in agreement with the observations made by Fayrouz et $a l^{18}$ and Sudikshya et $a .^{12}$ In contrast, Desai Bhavana et al, ${ }^{15}$ Sangam et al, ${ }^{13}$ Prateek and Pillai,19 and Umraniya et $\mathrm{al}^{20}$ reported a higher incidence of loops and arches in the A Rh pve group, and of whorls in the A Rh -ve blood group. Shivhare et $a l^{11}$ observed a higher frequency of loops and whorls in the A Rh -ve blood group.

In the present study, in the B blood group, the frequency of loops and arches was higher among the $\mathrm{Rh}$ pve subjects, and the incidence of whorls was higher among the Rh + ve subjects. This observation correlates with those of the studies by Umra-niya et $a l,{ }^{20}$ Sudikshya et $a l,{ }^{12}$ and Desai et al. ${ }^{15}$ In agreement with other studies, ${ }^{12,18}$ this differencewas not significant in the present study. But Deopa et $\mathrm{al}^{14}$ observed a greater percentage of both loops and arches in the $\mathrm{B}$ $\mathrm{Rh}$-ve and whorls in the B Rh pve blood group. Fayrouz et $\mathrm{ll}^{18}$ observed a higher frequency of both loops and whorls in the B Rh -ve blood group, and of arches in the B Rh pve blood group. And Shivhare et $\mathrm{Bl}^{11}$ only observed a high percentage of loops in the B Rh -ve group, andwhorls and arches were higher in the B Rh pve blood group.

In the $\mathrm{AB}$ blood group, only loops and arches were observed on both hands of the Rh -ve group; whorls were not observed. Therefore, the frequency of loops (70\%) and arches (30\%) is higher than that of the $A B$ Rh pve blood group loops (61.67\%) and arches (5\%).
This observation was statistically significant $(p>0.05)$. In the $\mathrm{AB} \mathrm{Rh}$-ve blood group, all three fingerprint patterns were observed by Desai et al, ${ }^{15}$ Bharadwaja et $a l,{ }^{17}$ and Fayrouz et $a l .{ }^{18}$ However, Radhika et $\mathrm{al}^{21}$ and Prateek and Pillai ${ }^{19}$ did not observe any of the three fingerprint patterns in the $\mathrm{AB} \mathrm{Rh}$-ve group, while Sudikshya et $a l^{12}$ observed only loops (100\%). In the $\mathrm{AB} \mathrm{Rh}$-ve individuals, and Deopa et $\mathrm{al}^{14}$ observed only loops (80\%) and whorls (20\%).

In the O Rh pve blood group, the loops and whorls were highly frequent, while the frequency of arches was higher in the O Rh -ve group. In contrast, Desai et $a l^{15}$ observed a high incidence of whorls (70\%) in the O $\mathrm{Rh}$-ve group, while loops (59.11\%) and arches (12.35\%) were higher in the $\mathrm{O} R \mathrm{Rh}$ pve group. Sangam et $\mathrm{al}^{13}$ found a higher occurrence of loops (59.1\%) and whorls (40.8\%), but they did not observe arches in the O Rh -ve blood group. Fayrouz et $\mathrm{al}^{18}$ found a greater frequency of loops (54.3\%) in the O Rh pve blood group, and of whorls (50\%) and arches (20\%) in the O Rh -ve blood group. In a recent study, Sudikshya et $a l^{12}$ observed a higher percentage of loops (54\%) and arches (7\%) in the $\mathrm{O}$ Rh -ve group, and whorls (41.35\%) were dominant in the $\mathrm{O}$ Rh pve blood group. Interestingly, in the studies by Fayrouz et $a l^{18}$ and Sudikshya et al, ${ }^{12}$ this difference was not statistically significant ( $p>0.05$ ), which is in line with the present study.

Regarding the fingerprint pattern on different fingers, the frequency of loops was higher on the thumb and on the middle and little fingers in the A, B and $\mathrm{O}$ blood groups. Similarly, Bharadwaja et $a l^{17}$ and Jain et $a l^{22}$ also observed a high frequency of loops on the little and middle fingers in all blood groups, while the incidence of whorls in blood groups A, B and $\mathrm{O}$ was higher on the index and ring fingers. Still regarding those two studies, in the $A B$ blood group, 
the incidence of loops was higher, followed whorls and arches on all of the fingers. In the present study, the incidence of arches in blood groups $\mathrm{B}$ and $\mathrm{O}$ was higher on the index and middle fingers. Interestingly, the incidence of arches was lower on the thumbs and little fingers of the subjects in blood group A. Sudikshya et $a l^{12}$ and Bharadwaja et $a l^{17}$ also reported a higher incidence of arches on the index finger, but in every blood group. And Jain et $a^{22}$ reported a high frequency of arches on the index finger in blood groups $\mathrm{A}$ and $\mathrm{B}$, and in blood groups $\mathrm{AB}$ and $\mathrm{O}$, the incidence of arches was higher on the little finger (35.7\%) and the thumb (9.1\%). Deopa et $\mathrm{al}^{14}$ observed a higher frequency of arches on the index fingers of the subjects with blood groups $\mathrm{B}, \mathrm{AB}$ and $\mathrm{O}$. In the present study, the fingerprint pattern distribution on different fingers showed a highly significant difference in blood groups $\mathrm{A}, \mathrm{B}$ and $\mathrm{O}$, whereas in the $\mathrm{AB}$ blood group, the difference in distribution was not significant. However, Sudikshya et $\mathrm{al}^{12}$ and Fayrouz et al observed a statistically significant difference in the distribution of fingerprint patterns in every blood group.

\section{Conclusion}

Loops are the most commonly observed fingerprint pattern, and arches are the least frequent in both males and females and in all blood groups. In the comparison between genders, the percentage of whorls and arches was higher among females, while the percentage of loops was higher among males.

The incidence of loops is more associated with the thumb and the middle and little fingers in the subjects in blood groups A, B \& O, and the frequency of whorls was higher on the index and ring fingers in the A, B and $\mathrm{O}$ blood groups. Individuals in blood group $\mathrm{AB}$ had a higher frequency of loops on the middle, ring and index fingers, and of whorls on the thumb and little finger.

The authors of the present study conclude that the distribution of fingerprint patterns is not related to gender, but it is related to individual digits and blood groups. The relation ship between finger print and blood group can be useful in forensic medicine for the identification of criminals; it can also be used in the prediction of certain blood related diseases.

\section{References}

1. Cummins $H$, Midlo $C$. Palmar and plantar epidermal ridge con figurations (dermatoglyphics) in European-Americans. Am J Phys Anthropol 1926;9:471-502.

2. Hamilton WJ, Mossman HW. Integumentary system: the skin and its derivatives, in Human Embryology: Prenatal Development of Form and Function, p. 567, W., Great Britain, UK, 4th ed. Heffer \& Sons Ltd; 1972.

3. Vij K. Textbook of Forensic Medicine and Toxicology. 3rd ed. New Delhi:Elsevier; 2005:89-91.

4. The critical stage of friction ridge and pattern formation. J Forensic Identification 2002;52(01):35-85.

5. Faulds $H$. The skin furrows of the hand. Nahest 1880;22:605.

6. Galton F. Finger Prints. London: Macmillan and Co; 1892.

7. Pillay VV. Textbook of Forensic Medicine and Toxicology. $15^{\text {th }}$ ed. Hyderabad: Paras Medical Publishers; 2009:53-94.

8. Babu SS, Powar BP, Khare ON. Palmer Dermatoglyphics in Pulmonary Tuberculosis. J Anat Soc India 2005;54:64-66.

9. Aird I, Bentall HH, Roberts JA. A relationship between cancer of stomach and the ABO blood groups. BMJ 1953;1(4814):799-801 10. Subrahmanyam BV. "Personal identity," in Modi's Medical Jurisprudence and Toxicology. 71-77Butterworths IndiaNew Delhi, India, 22nd edition, 1999.

11. Shivhare PR, Sharma SK, Ray SK, Minj A, Saha K. Dermatoglyphic Pattern in Relation to ABO, Rh Blood Group and Gender among the Population of Chhattisgarh. Int J Sci Stud 2017;4(11):61-65.

12. Kc S, Maharjan N, Adhikari N, Shrestha P. Qualitative Analysis of Primary Fingerprint Pattern in Different Blood Group and Gender in Nepalese. Anat Res Int 2018;2018:2848974.
13. Sangam MR, Babu AR, Krupadanam K, Anasuya K. Fingerprint Pattern in Different Blood Groups. J Indian Acad Forensic Med 2011;33(04):343345.

14.Deopa D, Prakash C, Tayal I. A study of fingerprint in relation to gender and blood group among medical students in Uttarakhand region. J Indian Acad Forensic Med 2014;36(01):23-27.

15. Desai B, Jaiswal R, Tiwari P, Kalyan JL. Study of fingerprint patterns in relationship with blood group and gender. Res J Forensic Sci 2013;1(01):15-17.

16. Ekanem AU, Abubakar H, Dibal NI. A Study of Fingerprints in Relation to Gender and Blood Group among Residents of Maid- uguri, Nigeria. J Dent Med Sci 2014;13(08):18-20.

17. Bharadwaja A, Saraswat PK, Agrawal SK, Banerji P, Bharadwaj S. Pattern of fingerprints in different $A B O$ blood groups. J Forensic Med Toxicol 2004;21(02):49-52.

18. Fayrouz IN, Farida N, Irshad AH. Relation between fingerprints and different blood groups. J Forensic Leg Med 2012;19(01): 18-21.

19. Prateek R, Pillai KR. A study of fingerprints in relation to gender and blood group. J Indian Acad Forensic Med 2010;32(01):11-14.

20. Umraniya YN, Modi HH, Rajapati HK. Study of correlation of finger print pattern in different $A B O$, Rh blood groups. Int J Scientific Res Publ 2013;2(09):337-339.

21. Radhika RH. Pattern of fingerprints and their relation with blood groups. Indian J Basic Appl Med Res 2016;5(02):744-749

22. Jain A, Kasulkar A, Mardikar PA. A study of fingerprint pattern in relation to blood groups among medical students. Eur J Pharm Med Res 2017;4(10):298-300.
Received: March 13, 2019

Accepted: September 16, 2019
Corresponding author

Vasanthakumar Packirisamy

Email:vasan_ana@yahoo.co.in; pakirisamyv@ksau-hs.edu.sa 